\title{
Fetal-Maternal Hemorrhage: A Case and Literature Review
}

\author{
Nino Solomonia, M.D. ${ }^{1}$ Karen Playforth, M.D. ${ }^{2}$ Eric W. Reynolds, M.D., M.P.H. ${ }^{3}$ \\ ${ }^{1}$ Department of Pediatrics, Division of Neonatology \\ Address for correspondence and reprint requests Nino Solomonia, \\ 2 Department of Obstetrics and Gynecology, University of Kentucky, \\ College of Medicine, Lexington \\ ${ }^{3}$ Kosair Children's Hospital Neonatal Services, Louisville, Kentucky \\ M.D., Division of Neonatology, Department of Pediatrics, University of
Kentucky, College of Medicine, 800 Rose Street, MS 477, Lexington,
KY 40536 (e-mail: nso222@uky.edu).
}

Am J Perinatol Rep 2012;2:7-14.

\begin{abstract}
Keywords

- fetal-maternal hemorrhage

- neonatal anemia

Nearly all pregnancies include an insignificant hemorrhage of fetal blood into the maternal circulation. In some cases, the hemorrhage is large enough to compromise the fetus, resulting in fetal demise, stillbirth, or delivery of a severely anemic infant. Unfortunately, the symptoms of a significant fetal-maternal hemorrhage can be subtle, nonspecific, and difficult to identify at the time of the event. We present the case of a severely anemic newborn who was delivered in our facility with an extensive literature review.
\end{abstract}

\section{Case}

A female infant was born to a 21-year-old G1P0 mother at 28 weeks of gestation. Her prenatal laboratories were unremarkable except GBS-unknown. The blood type of the mother and infant was $\mathrm{O}$-positive. The pregnancy had been uncomplicated until 1 day before delivery, when the mother noted decreased fetal movement. She was evaluated at an outside hospital and then transferred to our high-risk obstetrics center. Although it was not known at the time of delivery, upon further investigation, the parents remembered that the mother had become ill 3 days before delivery with general malaise, illness, and abrupt development of generalized edema.

A biophysical profile scored 2 out of 8 . The infant was delivered via emergent cesarean section. Rupture of membranes occurred at delivery, with clear amniotic fluid. The fetus was in breech presentation with a double nuchal cord. The placenta was pale but otherwise normal. Very thin cord blood was noted by obstetric team.

The baby required aggressive resuscitation in delivery room, including intubation and positive pressure ventilation. The heart rate was initially low, but responded to airway management. The infant was noted to be very pale. Apgar scores were 1, 3, and 3 at 1, 5, and 10 minutes, respectively. The baby was intubated for both the 5 and 10 minute Apgar scores. Birth weight was $1335 \mathrm{~g}$.
The infant was transferred to neonatal intensive care for further evaluation and management. On admission, her vital signs were: temperature $=97.2 \mathrm{~F}$, heart rate $=145 \mathrm{bpm}$, respiratory rate $=40$ on conventional mechanical ventilation with $100 \% \mathrm{O}_{2}$, blood pressure $(\mathrm{BP})=42 / 21 \mathrm{~mm} \mathrm{Hg}$ (meanBP $=$ $28 \mathrm{~mm} \mathrm{Hg}$ ), and $\mathrm{SpO}_{2}=92 \%$. Physical exam revealed a very pale preterm infant with little spontaneous movement and respiratory effort. Poor perfusion was noted with delayed capillary refill, equal but weak peripheral pulses. The liver was palpable at the level of the umbilicus. There was no evidence of peripheral edema or hydrops. Umbilical catheters were quickly placed and a bolus of normal saline was administered. Blood collected from the umbilical artery was thin and pink (-Fig. 1). Initial arterial blood gas revealed severe metabolic acidosis, $\mathrm{pH}<6.8, \mathrm{pCO}_{2} 63 \mathrm{~mm} \mathrm{Hg}$, and a metabolic component beyond the limit of the point-of-care analysis equipment ("to large to calculate"). The hematocrit was 5\%, with hemoglobin of $1.4 \mathrm{~g} / \mathrm{dL}$. The white blood cell count was 18.1/uL and platelet count was 79,000/uL. Nucleated red blood cell count was 104/100 WBCs. Serum lactate was $15.8 \mathrm{mmol} / \mathrm{L}$. Due to persistent hypoxemia, the baby received surfactant and was changed to high-frequency oscillatory ventilation and nitric oxide was added. A sepsis evaluation and empiric antibiotics were started. TORCH (toxoplasmosis, syphilis, rubella, cytomegalovirus, and herpes) titers were obtained and were later noted to be normal. The placenta was sent for pathological

\section{received}

August 18, 2011

accepted after revision

September 26, 2011

published online

November 25, 2011
Copyright (C 2012 by Thieme Medical Publishers, Inc., 333 Seventh Avenue, New York, NY 10001, USA. Tel: +1(212) 584-4662.
DOI http://dx.doi.org/ 10.1055/s-0031-1296028. ISSN 2157-6998. 

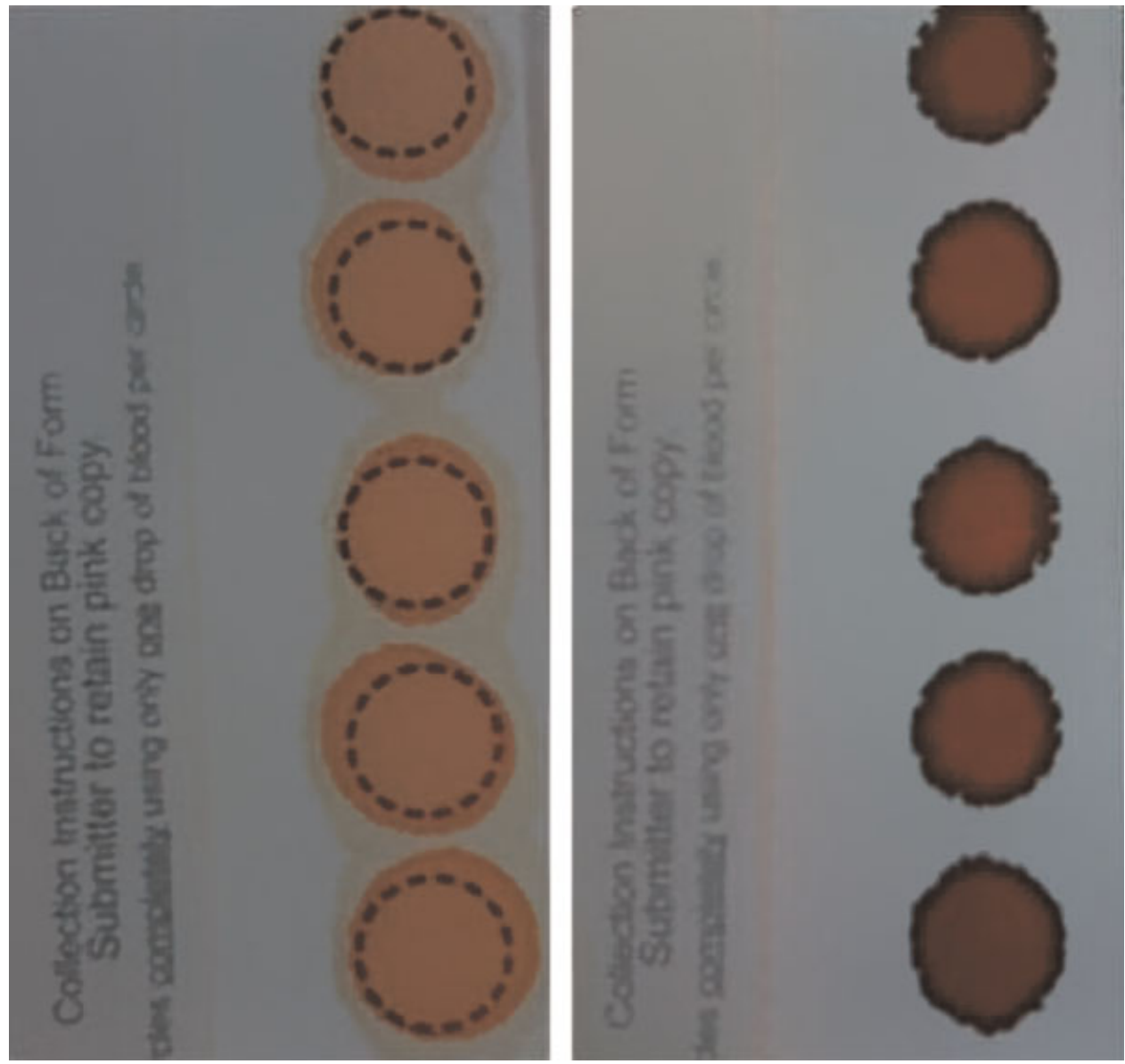

Figure 1 Filter paper for standard newborn screening collected from the infant in our case presentation. A normal appearing sample is included for comparison. Notice that the sample from our infant is pale, pink and separates on the paper.

evaluation. Aside from the pale appearance, no abnormalities were detected. There were biochemical markers of hypoxic injury to the liver and kidneys (abnormal aspartate aminotransferase and alanine aminotransferase, increased creatinine and blood urea nitrogen).

An immediate transfusion of O-negative packed red blood cells $(15 \mathrm{ml} / \mathrm{kg})$ was ordered due to the empiric clinical diagnosis of severe anemia as evidenced by the appearance of the blood that was drawn from the UAC. When the hematocrit result returned from laboratory, revealing the true extent of the profound anemia, a partial exchange transfusion was performed with packed red blood cells (using whole blood would have delayed the intervention by up to 6 hours). The post-transfusion hematocrit was 35\%. She received a platelet transfusion and two more packed red cell transfusions over the next 2 days.

The baby's blood gases continued to show profound metabolic acidosis for several hours after delivery despite aggressive buffering. Eventually, the pH increased to 7.42 at 7 hours of age.

Echocardiogram on day-of-life (DOL) 1 revealed persistent pulmonary artery pressure at $40 \mathrm{~mm} \mathrm{Hg}$ and a patent ductus arteriosus with bidirectional shunting. Cardiac function was normal. Cranial ultrasound on DOL 1 showed no intraventricular hemorrhage (IVH). Later on DOL 1, the infant demonstrated abnormal movements, which were suggestive of seizures, and was started on phenobarbital. The infant was weaned from respiratory support and extubated on DOL 5. Serial cranial ultrasounds showed progressively worsening IVH, eventually reaching grade IV. There was also progressive hydrocephalus which required serial lumbar punctures and eventually a ventricular reservoir (-Fig. 2), results which were confirmed with magnetic resonance imaging. Retrospectively, there has been discussion as to the nature of the hydrocephalus being either ex vacuo or actually a large porencephalic cyst related to the severe hypoxic injury. Nevertheless, the ventriculomegaly stabilized and the infant did not require shunt placement.

Over the course of her stay in the neonatal intensive care unit, the infant required supplemental oxygen, had feeding difficulties and temperature instability, all of which contributed to her prolonged length of stay. She was discharged to home on DOL 72 with an apnea monitor.

A Kleihauer-Betke (KB) test performed on the mother's blood shortly after delivery showed 3.8\% fetal red cells suggestive of $\sim 190$ cc of fetal blood in the maternal circulation, a volume larger than the expected total blood volume for an infant this size.

\section{Discussion}

The ability of fetal red cells to cross into maternal circulation was first hypothesized by Wiener in $1948,{ }^{1}$ and was later 


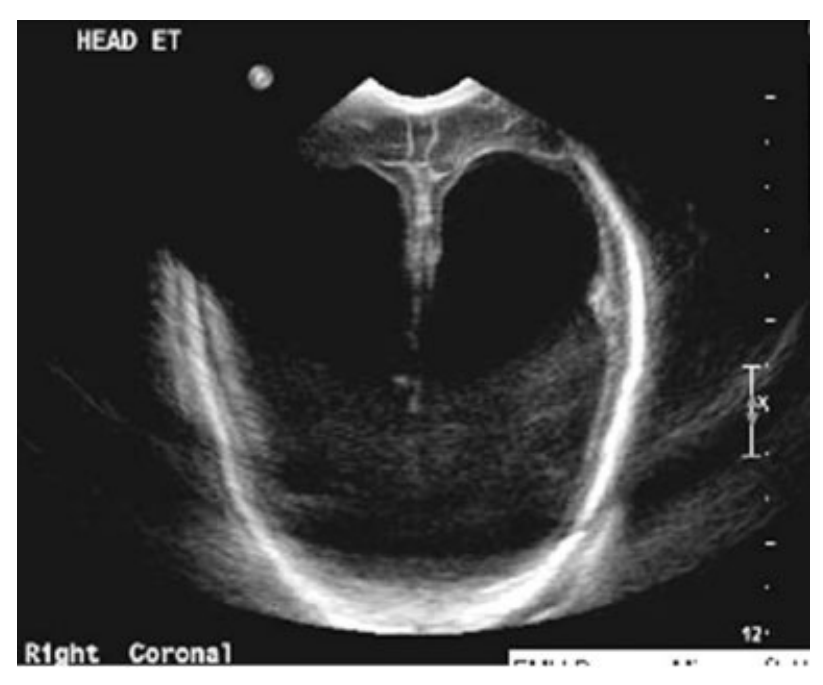

Figure 2 Cranial ultrasound from the infant in our case showing severe hydrocephalus. There remains discussion among the treating physicians as to the cause of the findings. Possible explanations include posthemorrhagic hydrocephalus, hydrocephalus ex vacuo, or a large porencephalic cyst. Regardless of the etiology, long-term developmental disability is expected.

confirmed as a cause of neonatal anemia by Chown in $1954 .^{2}$ It is now known that the placenta can be a conduit for movement of both nucleated cells and red corpuscles in a bidirectional fashion between the mother and fetus. ${ }^{3}$ Laube suggested that fetal-maternal hemorrhage (FMH) was responsible for nearly $14 \%$ of unexplained fetal deaths and $3 \%$ of all fetal deaths. ${ }^{4}$

It seems that nearly all pregnancies result in some fetal red cells crossing into maternal circulation. ${ }^{3}$ Zipursky et al, estimated the incidence of FMH at 21 to $75 \%$ of pregnancies. ${ }^{5}$ Another author reported 15 to $31 \%$ of pregnancies with some degree of FMH, but only 1.5 to $6 \%$ with bleed volume $>0.1$ mL. ${ }^{6}$ In 1997, Jorgansen proposed an incidence of 39 to $95 \%$ of pregnancies resulting in some fetal blood in maternal circulation. ${ }^{7}$ Bowman suggested that $75 \%$ of all pregnancies have a degree of FMH. ${ }^{8}$ Sebring showed that $93 \%$ of FMHs result in $<0.5 \mathrm{~mL}$ of fetal blood being transferred. ${ }^{9}$ These results were supported by Dupre et al, who showed that $98 \%$ of FMHs result in $<0.1 \mathrm{~mL}$ of fetal blood being transferred. ${ }^{10}$

Some authors have attempted to define a clinically significant, or "massive," FMH by taking into account the volume of blood lost from the fetus. Cardwell defined a massive hemorrhage as one half of the infant blood volume. ${ }^{11}$ Other authors have used a volume of $30 \mathrm{~mL}$ as the definition of massive because this is the volume of fetal blood that will require one full unit of Rh immune globulin to prevent Rh sensitization in a mother with concerns for alloimmunization. ${ }^{12}$ Another author chose $80 \mathrm{~mL}$ as an important volume of blood loss because, at this volume, patients in their study population exhibited "anemia," although a strict definition of anemia was not given. ${ }^{13}$ A review article focused on bleeding volumes of $>50 \mathrm{~mL}$ because this volume was "likely to affect the outcome of the pregnancy." ${ }^{14}$ Still others have proposed $150 \mathrm{~mL}$ as an important blood volume. ${ }^{3}$ Other authors have attempted to correlate the volume of blood loss with clinical outcomes. Sebring found that hemorrhages of $>30 \mathrm{~mL}$ resulted in $26.5 \%$ of infants being stillborn or dying within 72 hours of birth. ${ }^{9}$ Other authors found an increased risk of "adverse outcome" with a blood loss of $20 \mathrm{~mL} / \mathrm{kg}$ of fetal weight. ${ }^{15}$ These authors also found that at $80 \mathrm{~mL} / \mathrm{kg}$ of blood loss two-thirds of the infants suffered in utero fetal demise.

Defining significant FMH in terms of volume lost alone is probably not helpful. Animal studies have shown that the rate of blood loss is another important factor. Brace found that in fetal sheep, a blood loss of $30 \%$ of the estimated total volume of the fetus was tolerated better if it occurred over 2 hours rather than 10 minutes. ${ }^{16,17}$ Blood loss over 2 hours resulted in a more rapid restoration of fetal intravascular volume, 3 hours versus 6 hours in the 10-minute group. Another sheep study found that red cell mass was normal 1 week after a loss of $40 \%$ of blood volume over a 2 -hour period. ${ }^{18}$

Given the ambiguity of the definition of a clinically relevant volume of hemorrhage, it is clear that more factors than blood volume alone are pertinent to this discussion. Indeed the rate of blood loss and the chronicity of the bleed are important. Gestational age is also an important factor given that the intravascular volume, as calculated in $\mathrm{mL} / \mathrm{kg}$, varies throughout the pregnancy and preterm infants are at increased risk for adverse outcomes that a term infant would not experience. The preterm infant is also likely to have less ability to tolerate the stress associated with a massive FMH.

Despite the problems with defining significant FMH by volume, many authors still present incidence data in terms of volume. One study reported an incidence of 1:1146 live births if a volume of $80 \mathrm{~mL}$ is used to define significance and 1:2813 if $150 \mathrm{~mL}$ is used. $^{13}$ This study also looked at a group of selected high-risk women whose blood samples were referred for fetal blood testing due to stillbirth, neonatal anemia, or fetal distress. In this selected population, $64.5 \%$ of these samples indicated a fetal hemorrhage of $>150 \mathrm{~mL}$. Forty-six percent of these infants had adverse outcomes. Another author suggested that hemorrhages of $>30 \mathrm{~mL}$ occur in 1 out of 300 otherwise normal pregnancies. ${ }^{9}$ In a more recent article, hemorrhages of $>20 \mathrm{~mL}$ were found to occur in 4.6/1000 live births, volumes of $>30 \mathrm{~mL}$ occurred in 3.8/1000 live births, and $>80 \mathrm{~mL}$ occur in $0.7 / 1000$ live births. ${ }^{15}$ Recurrent FMH in subsequent pregnancies has been reported in a few case reports. ${ }^{19-21}$ However, these events are quite rare.

FMH can physiologically occur as early as 4 weeks of gestation with the combination of vascularization of the chorionic villi and initiation of contraction in the primitive heart. ${ }^{22}$ Fetal placental blood vessels have higher blood pressure than the intervillous space. If there is disruption of the maternal-fetal barrier, hemorrhage will occur from the fetus to the maternal circulation. In the setting of $A B O$ incompatibility, the maternal clotting system may be activated, limiting the effect of the hemorrhage. If there is ABO compatibility, clotting is less likely to be activated and the hemorrhage may continue with dramatic effects. ${ }^{22}$ This was shown as early as 1968 when Devi et al hypothesized that 
placental clots were protective against extension of massive fetal hemorrhage. ${ }^{23}$

FMH can follow maternal abdominal trauma. ${ }^{24,25}$ Hemorrhages have occurred following maternal falls and motor vehicle accidents. ${ }^{6}$ It has also been linked to various obstetric procedures such as external cephalic version, ${ }^{26}$ manual removal of a retained placenta, ${ }^{27}$ or amniocentesis. ${ }^{6,28,29}$ Placental anomalies such as tumors or chorioangiomas, $6,30,31$ abruption, $^{32}$ and monochorionic-monoamnionic twins ${ }^{33}$ have also been identified as causes of abruption. However, $82 \%$ of cases arise spontaneously, with no identifiable history of an inciting event. ${ }^{14}$

The initial symptoms of an acute FMH are often subtle and nonspecific. Most are diagnosed retrospectively after an infant is stillborn, experiences unexplained fetal distress or is born with symptoms consistent with a hemorrhage. ${ }^{34}$ Prenatally, the mother may present with a history of decreased or absent fetal movement. ${ }^{13}$ A 1997 study found in $27 \%$ of cases, decreased or absent fetal movement was the presenting symptom of a fetal hemorrhage. ${ }^{14}$ Other forms of fetal distress were present in $7 \%$ of cases and IUGR was the presenting symptom in $3 \%$. Unexpected stillbirth was the only presenting sign in $12.5 \%$ of cases. Fetal heart rate monitoring may show a sinusoidal pattern, a lack of acceleration, and recurrent late decelerations. ${ }^{35,36}$ The sinusoidal heart rate pattern, with or without decreased fetal movement, is a common presenting sign in published reports of FMH. ${ }^{14,19,37,38}$ In the event of massive fetal blood loss, the mother may experience a transfusion reaction expressed as nausea, edema, fever, and chills. ${ }^{39,40}$ If the mother and fetus have Rh incompatibility, sensitization can occur and $\mathrm{Rh}$ immune globulin injection is indicated. ${ }^{41}$

If the fetus can compensate for the blood loss, the pregnancy may continue to delivery of an infant with varying degrees of anemia. Initially, the fetus may increase cardiac output, with fetal tachycardia reported as a presenting symptom. ${ }^{42}$ The increased cardiac output results in increased blood flow in the fetus that can be measured with Doppler ultrasound studies. Sueters correlated increased flow in the fetal middle cerebral artery with anemia. ${ }^{38}$ Flow in the umbilical vessels can also be increased. ${ }^{38}$ Evidence of increased hemopoetic activity may be present in the infant with evidence of placental and hepatic hemopoesis and erythroblasts and/or reticulocytes present in the neonate's peripheral blood smear. ${ }^{14}$

In the setting of uncompensated anemia, the fetus may develop high-output heart failure and hydrops fetalis ${ }^{43}$ due to changes in the hydrostatic (oncotic) pressure. The triad of decreased fetal movement, sinusoidal heart rate, and hydrops fetalis are symptoms of severe anemia associated with massive FMH. However, this combination is a late presentation of the disease. ${ }^{13,14}$

When a massive fetal hemorrhage occurs, the only hope for improved outcome is prompt recognition and intervention. ${ }^{13}$ Unfortunately, the symptoms as described are nonspecific and subtle. In the uncommon event that fetal anemia is recognized before delivery, the risks and benefits of immediate delivery should be evaluated. If the infant is near-term gestation, immediate cesarean delivery is indicated. C-section is the delivery method of choice because the compromised placenta may not support the stress of labor. ${ }^{44}$ If the fetus is still of preterm gestation, in utero transfusion can be considered and has been shown to be an effective method to safely temporize the effects of fetal anemia. ${ }^{45,46}$ If the hemorrhage continues, serial transfusions may be indicated. Giacoia reported providing 17 in utero transfusions to 9 infants, 8 of whom survived. $^{14}$

Neonatal anemia has been reported to be the presenting sign in $35 \%$ of cases. ${ }^{14}$ In severe cases, signs of shock and circulatory failure are present. ${ }^{47}$ If anemia is present, it should be corrected slowly to avoid volume overload and exacerbation of heart failure. In cases with the most profound anemia, exchange transfusion may allow for rapid correction of the anemia while avoiding the complications associated with excessive volume or cardiac compromise. ${ }^{48,49}$ Exchange transfusion with whole blood may be preferred. However, if the child's clinical condition is unstable, packed red cells may be more readily available. Calcium gluconate, protein, and other blood products may need to be replaced after an exchange transfusion.

When a FMH is suspected, maternal blood can be checked for the presence of fetal red blood cells. Of historical significance is the Rosette test. This is a qualitative screening test that identifies Rh-positive blood in Rh-negative mothers. ${ }^{50}$ Even if the Rosette test is positive, a quantitative test is still required. Hemoglobin electrophoresis has been used to detect fetal hemoglobin in one case report. ${ }^{19}$ However, this test can be distorted by pathologic conditions that result in increased hemoglobin $\mathrm{F}(\mathrm{Hg}-\mathrm{F})$ or the physiologic rise in $\mathrm{Hg}-\mathrm{F}$ associated with pregnancy. Flow cytometry is less labor intensive than other tests that are available but requires specific equipment that may not be widely available. Flow cytometry can identify cells by size (fetal red cells are larger than maternal cells). ${ }^{51}$ This phenomenon is also responsible for the increased red cell distribution width detectible in maternal blood when fetal cells are present. ${ }^{37}$ Fetal cells can also be tagged with monoclonal antibodies that can be identified with flow cytometry techniques. ${ }^{52}$ Following fetal hemorrhage, increased levels of $\alpha$-fetoprotein (AFP) can be measured in maternal serum. While AFP is stable for storage and not influenced by red cell agglutination, AFP levels vary with gestational age, complicating the estimation of the fetal hemorrhage. $^{9}$

The most common test for fetal blood in maternal circulation is the acid elution test commonly referred to as the KB test. $^{53}$ In this test, maternal blood is fixed, washed with acid, and then stained. The maternal cells are not stable after the acid treatment and do not take-up the stain, appearing as ghost cells on the slide. Several cells are manually counted and the volume of hemorrhage can be calculated by accounting for the percentage of fetal cells present on the slide extrapolating to the expected maternal blood volume. Unfortunately, the KB test is affected by many factors that result in inaccurate interpretation of the results. ${ }^{9}$ Blood used for the $\mathrm{KB}$ test can be affected by temperature, $\mathrm{pH}$, and the time since the blood sample was collected. The expected maternal blood 
volume varies with gestational age and can be affected by the presence of maternal anemia. In some cases, the fetal cells may not stain as well as expected, resulting in inaccurate interpretation of the results. After fetal transfusion, tests for fetal hemoglobin in maternal circulation are no longer helpful in assessing the extent of continued bleeding as transfused blood cells will be of adult origin and therefore not distinguishable in maternal circulation. Likewise, maternal hemoglobinopathies that result in increased fetal hemoglobin will also make interpretation of these tests difficult. The problems with the KB test can result in calculation of blood volumes greater than are likely possible in most physiologic conditions. One report in the literature included calculation of $400 \mathrm{~mL}$ of fetal blood lost to a mother who was known to be anemic. $^{37}$ Another report calculated $410 \mathrm{~mL}$ of fetal blood loss. ${ }^{22}$ Another report calculated $700 \mathrm{~mL}$ of fetal blood loss following a chronic hemorrhage. ${ }^{54}$

Since minor FMHs are nearly ubiquitous in pregnancy, the overall outcomes from these events are negligible. However, in cases of massive bleeding, morbidity and mortality rates are quite high and are directly related to the degree of hypovolemic shock experienced by the fetus/neonate. ${ }^{14}$ At birth, these infants are often pale with evidence of poor perfusion. Respiratory distress is common. It may present as a general respiratory failure. Also, since bicarbonate is usually found in the red blood cells, the severe anemia depletes the infant's bicarbonate stores, leading to a profound acidosis which can exacerbate pulmonary hypertension. The acidosis can be difficult to treat because red blood cells are the natural compartment for bicarbonate in blood. The infant may appear hydropic or have evidence of heart failure, such as cardiomegaly or hepatomegaly. Bleeding disorders can occur with disseminated intravascular coagulation having been reported. Central nervous system dysfunction is common with hypoxic-ischemic encephalopathy, cerebral infarction, IVH, and periventricular leukomalacia all having been reported. ${ }^{14}$ Fay first reported a link between FMH and cerebral palsy. ${ }^{48}$ However, actual occurrence rates are difficult to assess. A study of FMHs in Canada found adverse outcomes in $46 \%$ of affected infants, with 10 of 26 patients dead within 6 months of birth and 1 infant with spastic quadripalegia. ${ }^{13}$ Giacoia reported no difference in long-term outcomes for lowest hemoglobin levels greater than or less than $6 \mathrm{~g} / \mathrm{dl}$ or estimated bleed volumes greater than or less than $200 \mathrm{~mL}^{14}$ However, given the problems with chronicity of bleeding, estimating the bleed volume and the fetus' ability to compensate for blood loss, these findings are not necessarily surprising.

When an infant is born with unexpected anemia, in addition to $\mathrm{FMH}$, physicians should consider alternative diagnoses such as isoimmune hemolytic anemia (Rh incompatibility), or autoimmune causes, congenital infections that result in bone marrow suppression (TORCH) or bacterial sepsis. ${ }^{55} \mathrm{~A}$ sepsis evaluation and empiric antibiotics are warranted. Congenital erythrocyte defects of structure (membrane defects: spherocytes, elliptocytes) or function (G6PD, pyruvate kinase deficiency) or congenital hemoglobinapathies ( $\alpha$-thalassemia) can also cause anemia. ${ }^{55}$ Con- genital hypoplastic anemia (Diamond-Blackfan syndrome, congenital leukemia) should also be considered in the differential diagnosis. ${ }^{55}$

Given that the etiology of FMH events is unclear, it is difficult to quantify the risk in future pregnancies for the mother and difficult to recommend strategies to prevent recurrence. It is reasonable to counsel the patient on the importance of fetal movement counts and to institute antepartum evaluation in the third trimester. This should include a reasonable schedule of nonstress tests and sonograms to assess for signs of anemia and hydrops. Serial KB tests can be considered in cases with a history of previous catastrophic FMH or with an obstetric history concerning for possible multiple risk factors for poor outcome. However, once a FMH has occurred, the interpretation of serial $\mathrm{KB}$ tests in that pregnancy is controversial.

The infant in our case presented with many of the classic signs associated with FMH. The pregnancy had been normal until she presented with decreased fetal movement. After delivery, she related a history of general illness and increased edema 3 days before delivery, symptoms which were not recognizable at the time as what we now hypothesize to have been a transfusion reaction. The fetal heart tracing, while not sinusoidal, showed absent beat-tobeat and long-term variability, signs of a severely compromised fetus. The low score on the biophysical profile prompted an emergent cesarean delivery. The infant was immediately recognized to be pale with poor perfusion and symptoms of hypovolemic shock. The infant had a severe metabolic acidosis related to the lack of red blood cells available to carry buffer. The infant had severe respiratory distress and elevated pulmonary artery pressure, treated with aggressive ventilation and inhaled nitric oxide. There was an elevated nucleated red blood cell count, consistent with increased hematopoesis. The hemoglobin of $1.4 \mathrm{gm} / \mathrm{dl}$ was the lowest level we could find in the literature in a surviving infant. Unfortunately, the infant suffered a severe hypoxic brain injury that resulted in loss of white matter and hydrocephalus. Long-term follow-up is pending, but we necessarily remain pessimistic about her neurologic outcome.

\section{Conclusion}

We have presented a case of severe FMH with possibly the lowest blood hemoglobin level in a surviving infant ever reported in the literature. Unfortunately, the symptoms of an acute hemorrhage are nonspecific. Physicians should consider this diagnosis when a pregnant mother presents with decreased fetal movement and fetal distress, especially if the fetal heart tracing is sinusoidal. The diagnosis should also be considered when there is an unexplained fetal demise or delivery of a severely anemic infant, with or without evidence of hypovolemic shock. The KB test, as with all of the current tests for estimating the size of a fetal hemorrhage, is imperfect. Long-term outcome for infants affected by massive FMH is likely to be poor, with death or CNS dysfunction likely. 


\section{References}

1 Wiener AS. Diagnosis and treatment of anemia of the newborn caused by occult placental hemorrhage. Am J Obstet Gynecol 1948;56(4):717-722

2 Chown B. Anaemia from bleeding of the fetus into the mother's circulation. Lancet 1954;266(6824):1213-1215

3 Wylie BJ, D’Alton ME. Fetomaternal hemorrhage. Obstet Gynecol 2010;115(5):1039-1051

4 Laube DW, Schauberger CW. Fetomaternal bleeding as a cause for "unexplained" fetal death. Obstet Gynecol 1982;60(5):649-651

5 Zipursky A, Hull A, White FD, Israels LG. Foetal erythrocytes in the maternal circulation. Lancet 1959;1(7070):451-452

6 Renaer M, Van de Putte I, Vermylen C. Massive feto-maternal hemorrhage as a cause of perinatal mortality and morbidity. Eur J Obstet Gynecol Reprod Biol 1976;6(3):125-140

7 Jørgensen J. Feto-maternal bleeding. During pregnancy and at delivery. Acta Obstet Gynecol Scand 1977;56(5):487-490

8 Bowman JM, Pollock JM, Penston LE. Fetomaternal transplacental hemorrhage during pregnancy and after delivery. Vox Sang 1986;51(2):117-121

9 Sebring ES, Polesky HF. Fetomaternal hemorrhage: incidence, risk factors, time of occurrence, and clinical effects. Transfusion 1990;30(4):344-357

10 Dupre AR, Morrison JC, Martin JN Jr, Floyd RC, Blake PG. Clinical application of the Kleihauer-Betke test. J Reprod Med 1993;38 (8):621-624

11 Cardwell MS. Fetomaternal hemorrhage. When to suspect, how to manage. Postgrad Med 1987;82(5):127-130

12 Pollack W, Ascari WQ Kochesky RJ, O'Connor RR, Ho TY, Tripodi D. Studies on Rh prophylaxis. 1. Relationship between doses of anti-Rh and size of antigenic stimulus. Transfusion 1971;11(6): 333-339

13 de Almeida V, Bowman JM. Massive fetomaternal hemorrhage: Manitoba experience. Obstet Gynecol 1994;83(3):323-328

14 Giacoia GP. Severe fetomaternal hemorrhage: a review. Obstet Gynecol Surv 1997;52(6):372-380

15 Rubod C, Deruelle P, Le Goueff F, Tunez V, Fournier M, Subtil D. Long-term prognosis for infants after massive fetomaternal hemorrhage. Obstet Gynecol 2007;110(2 Pt 1):256-260

16 Catalano PM, Capeless EL. Fetomaternal bleeding as a cause of recurrent fetal morbidity and mortality. Obstet Gynecol 1990; 76(5 Pt 2):972-973

17 Dupont G, Povlsen JV. [Repeated episodes of massive fetomaternal hemorrhage in the same woman]. Ugeskr Laeger 1991;153 (39):2750

18 Maass B, Wurfel B, Fusch C. Recurrent fetomaternal transfusion in two consecutive pregnancies. Prenat Diagn 2001;21;788-793

19 Brace RA. Mechanisms of fetal blood volume restoration after slow fetal hemorrhage. Am J Physiol 1989;256(5 Pt 2):R1040-R1043

20 Brace RA, Cheung CY. Fetal blood volume restoration following rapid fetal hemorrhage. Am J Physiol 1990;259(2 Pt 2):H567H573

21 Gruslin-Giroux A, Shields LE, Widness JA, Brace RA. Fetal plasma iron and restoration of red blood cell mass after hemorrhage of the ovine fetus. Am J Obstet Gynecol 1997;177(5):1172-1177

22 Tseng LL, Didone AM, Cheng CS. Severe anemia in a newborn due to massive fetomaternal hemorrhage: report of one case. Acta Paediatr Taiwan 2005;46(5):305-307

23 Devi B, Jennison RF, Langley FA. Significance of placental pathology in transplacental haemorrhage. J Clin Pathol 1968;21(3):322-331

24 Bickers RG, Wennberg RP. Fetomaternal transfusion following trauma. Obstet Gynecol 1983;61(2):258-259

25 Rose PG, Strohm PL, Zuspan FP. Fetomaternal hemorrhage following trauma. Am J Obstet Gynecol 1985;153(8):844-847

26 Nord E, Blaschke E, Green K, Thomassen P. 100 cases of external cephalic version, with special reference to fetomaternal transfusion. Acta Obstet Gynecol Scand 1989;68(1):55-58
27 Queenan JT, Nakamoto M. Postpartum immunization: the hypothetical hazard of manual removal of the placenta. Obstet Gynecol 1964;23;392-395

28 Queenan JT, Adams DW. Amniocentesis: a possible immunizing hazard. Obstet Gynecol 1964;24;530-532

29 Bowman JM, Pollock JM. Transplacental fetal hemorrhage after amniocentesis. Obstet Gynecol 1985;66(6):749-754

30 Sims DG, Barron SL, Wadehra V, Ellis HA. Massive chronic fetomaternal bleeding associated with placental chorioangiomas. Acta Paediatr Scand 1976;65(2):271-273

31 Santamaria M, Benirschke K, Carpenter PM, Baldwin VJ, Pritchard JA. Transplacental hemorrhage associated with placental neoplasms. Pediatr Pathol 1987;7(5-6):601-615

32 Cardwell MS. Ultrasound diagnosis of abruptio placentae with fetomaternal hemorrhage. Am J Obstet Gynecol 1987;157(2): 358-359

33 Verco CJ, Jones WR. Monoamniotic twin pregnancy complicated by massive fetal-maternal haemorrhage. Aust N Z J Obstet Gynaecol 1981;21(3):186-187

34 Fliegner JRH, Fortune DW, Barrie JU. Occult fetomaternal haemorrhage as a cause of fetal mortality and morbidity. Aust N Z J Obstet Gynaecol 1987;27(2):158-161

35 Modanlou HD, Freeman RK. Sinusoidal fetal heart rate pattern: its definition and clinical significance. Am J Obstet Gynecol 1982;142 (8):1033-1038

36 Moise KJ. Diagnosis and management of massive fetomaternal hemorrhage. UpToDate. Available at: http://www.uptodate.com/ contents/diagnosis-and-management-of-massive-fetomaternalhemorrhage. Accessed July 12, 2011

37 Ishihara $\mathrm{H}$, Takahashi $\mathrm{H}$, Takeuchi $\mathrm{Y}$, et al. Massive fetomaternal hemorrhage: case report. Asia Oceania J Obstet Gynaecol 1990; 16(3):225-228

38 Sueters M, Arabin B, Oepkes D. Doppler sonography for predicting fetal anemia caused by massive fetomaternal hemorrhage. Ultrasound Obstet Gynecol 2003;22(2):186-189

39 Glasser L, West JH, Hagood RM. Incompatible fetomaternal transfusion with maternal intravascular lysis. Transfusion 1970; 10(6):322-325

40 Murphy KW, Venkatraman N, Stevens J. Limitations of ultrasound in the diagnosis of fetomaternal haemorrhage. BJOG 2000; 107(10):1317-1319

41 Cohen F, Zuelzer WW, Gustafson DC, Evans MM. Mechanisms of isoimmunization. I. The transplacental passage of fetal erythrocytes in homospecific pregnancies. Blood 1964;23;621-646

42 Nicolaides KH, Sadovsky G, Visser GH. Heart rate patterns in normoxemic, hypoxemic, and anemic second-trimester fetuses. Am J Obstet Gynecol 1989;160(5 Pt 1):1034-1037

43 Elliott JP. Massive fetomaternal hemorrhage treated by fetal intravascular transfusion. Obstet Gynecol 1991;78(3 Pt 2):520-523

44 Weisberg L, Kingdom J, Keating S, et al. Treatment options in fetomaternal hemorrhage: four case studies. J Obstet Gynaecol Can 2004;26(10):893-898

45 Fischer RL, Kuhlman K, Grover J, Montgomery O, Wapner RJ. Chronic, massive fetomaternal hemorrhage treated with repeated fetal intravascular transfusions. Am J Obstet Gynecol 1990;162(1): 203-204

46 Rouse D, Weiner C. Ongoing fetomaternal hemorrhage treated by serial fetal intravascular transfusions. Obstet Gynecol 1990;76(5 Pt 2):974-975

47 Holton ME. Unexpected anemia in a newborn. Tex Med 1989; 85(2):50-51

48 Fay RA. Feto-maternal haemorrhage as a cause of fetal morbidity and mortality. Br J Obstet Gynaecol 1983;90(5):443-446

49 Moya FR, Perez A, Reece EA. Severe fetomaternal hemorrhage. A report of four cases. J Reprod Med 1987;32(3):243-246

50 Stedman CM, Baudin JC, White CA, Cooper ES. Use of the erythrocyte rosette test to screen for excessive fetomaternal hemorrhage 
in Rh-negative women. Am J Obstet Gynecol 1986;154(6): 1363-1369

51 Mollison PL. Quantitation of transplacental haemorrhage. BMJ 1972;3(5817):31-34

52 Davis BH, Olsen S, Bigelow NC, Chen JC. Detection of fetal red cells in fetomaternal hemorrhage using a fetal hemoglobin monoclonal antibody by flow cytometry. Transfusion 1998;38(8): 749-756
53 Kleihauer E, Braun H, Betke K. [Demonstration of fetal hemoglobin in erythrocytes of a blood smear]. Klin Wochenschr 1957;35(12): 637-638

54 Willis C, Foreman CS Jr. Chronic massive fetomaternal hemorrhage: a case report. Obstet Gynecol 1988;71(3 Pt 2):459-461

55 Eyal FG. Anemia. In: Gomella TL, Cunningham MD, Eyal FG, eds. Neonatology: Management, Procedures, On-Call Problems, Dis ease, and Drugs. 6th ed. New York, NY: McGraw-Hill Companies; 2009 